\title{
¿COYOTES O DEFENSORES DE MIGRANTES? CRIMINALIZACIÓN DEL ACTIVISMO PROMIGRANTE EN TIEMPOS DE CARAVANAS
}

\author{
Coyotes or defenders of migrants? \\ Criminalization of pro-migrants activism in caravan times
}

Eduardo Torre Cantalapiedra*

\begin{abstract}
Resumen. El objetivo de este trabajo es analizar la criminalización de los defensores de migrantes en México que se produjo coetáneamente al fenómeno de las caravanas de migrantes. A través de un estudio de caso, el de Pueblo Sin Fronteras, se analizan los discursos y acciones de las autoridades mexicanas que criminalizan a esta organización de la sociedad civil. Prestamos especial atención al uso del delito del tráfico de personas para hostigar y perseguir penalmente a los defensores de migrantes y construir una narrativa en su contra, esto es, a su coyotización práctica y discursiva.
\end{abstract}

Palabras clave: criminalización; coyotización; defensores de los derechos humanos de los migrantes; México; Honduras.

Abstract. The objective of this work is to analyze the criminalization of the defenders of migrants in Mexico that has occurred simultaneously to the phenomenon of migrant caravans. Through a case study, that of Pueblo Sin Fronteras, we analyze the speeches and actions of the Mexican authorities that criminalize this civil society organization. We pay special attention to the use of the human smuggling crime to harass and prosecute migrant defenders and build a narrative against them, that is, their practical and discursive coyotization.

Keywords: criminalization; coyotization; human rights defenders of migrants; Mexico; Honduras.

\footnotetext{
* Investigador Cátedras Conacyt, El Colegio de la Frontera Norte. Tijuana, México. E-mail: e.torreca@gmail.com. Orcid: 0000-0002-4074-3752.
} 


\section{Introducción}

En las últimas décadas han transitado por México ${ }^{1}$ cientos de miles de personas con destino a Estados Unidos, principalmente procedentes de Centroamérica (véase al respecto, El Colef et alii, 2019). Este fenómeno migratorio ha supuesto un desafío para los sucesivos gobiernos mexicanos en términos de gestión del mismo, que se ha acrecentado en los últimos años, cuando esta tarea se tiene que realizar enfrentando las presiones ejercidas por el gobierno de Donald Trump, que pretende que México detenga esta movilidad humana.

El primer año de mandato de Andrés Manuel López Obrador -que dio comienzo el 1 de diciembre de 2018- en lo que a la gestión migratoria se refiere ha estado marcada por tres hechos destacables: 1) la incursión de las caravanas de migrantes en México como una nueva forma de movilidad adoptada por los migrantes para el cruce de fronteras y el tránsito de territorios; 2) el ultimátum de imposición de aranceles a los productos mexicanos del presidente Trump si México no frenaba la migración en tránsito hacia Estados Unidos, que exigió a México redoblar sus esfuerzos en cuanto a la política de contención de la migración irregular; y 3) la que puede considerarse una imposición de Estados Unidos al gobierno mexicano de los Protocolos de Protección al Migrante (MPP, por sus siglas en inglés), por medio de los cuales miles solicitantes de asilo en Estados Unidos fueron devueltos a México para que esperasen su cita ante el juez de alguna corte estadounidense.

La importancia mediática y política de estos tres acontecimientos ha sido tal que han acaparado el interés de los investigadores, mientras que otros fenómenos que igualmente merecen ser estudiados han pasado desapercibidos; la criminalización de los defensores de los migrantes ${ }^{2}$ es uno de ellos. Dos informes elaborados por Amnistía Internacional (AI) (2019) y Front Line Defenders (FLD) et alii (2019) señalan que desde 2017, pero especialmente desde finales de 2018 -coincidiendo con las caravanas de migrantes- se ha producido un aumento significativo del hostigamiento, difamación, amenazas, detenciones, arrestos, deportaciones e investigaciones penales que, por el ejercicio de su labor solidaria, sufren los defensores de los derechos humanos (DD.HH.) de los migrantes por parte de actores gubernamentales de Estados Unidos, México, Guatemala y Honduras; con estas acciones están promoviendo

1 Aunque en mucho menor medida que Estados Unidos, México se ha convertido en los últimos años en lugar de asentamiento de migrantes (Faret, 2017; París Pombo, 2017).

2 Los defensores de los DD.HH de los migrantes son: "desde quienes ofrecen apoyo humanitario en las rutas migratorias [...], quienes documentan y visibilizan las violaciones a derechos humanos en las rutas migratorias y dan acompañamiento en trámites de regularización migratoria, quienes coordinan albergues [...], hasta quienes realizan incidencia con gobiernos y organismos internacionales para la formulación de legislación y políticas públicas con perspectiva de derechos humanos" (FLD et alii, 2019, p. 12). 
la criminalización de quienes defienden los DD.HH. de los migrantes para desalentar e impedir sus actividades humanitarias y con otros objetivos de índole política. Ambos informes evidencian que existe un cierto grado de cooperación entre los estados para llevar a cabo estas actuaciones. Asimismo, coinciden en destacar que el uso torticero del delito de tráfico de personas ha sido la herramienta predilecta para la criminalización de los defensores.

El objetivo de este trabajo es analizar la criminalización de los defensores de migrantes en México que se produjo coetáneamente al fenómeno de las caravanas de migrantes. Prestamos especial atención al uso del delito del tráfico de personas para hostigar y perseguir penalmente a los defensores de migrantes y construir una narrativa en su contra, esto es, a su coyotización práctica y discursiva.

Para el logro de tal objetivo, el trabajo está dividido en tres secciones. En la primera se presentan y examinan los conceptos relativos al tráfico de personas y se muestra cómo este delito ha sido empleado, más allá de la persecución de los coyotes, para incriminar a los defensores de los migrantes. Además, se exhibe la campaña de hostigamiento legal que Estados Unidos ha emprendido contra los defensores de los migrantes que ha influenciado las acciones del gobierno mexicano. En la segunda parte se expone sucintamente algunas cuestiones metodológicas de relevancia en el desarrollo de este trabajo. En la tercera, a través de un estudio de caso, el de Pueblo Sin Fronteras (PSF) ${ }^{3}$, se analizan los discursos y acciones de las autoridades mexicanas que criminalizan a esta organización de la sociedad civil (OSC) y se examina su relación con la campaña en contra de los defensores del gobierno de Estados Unidos.

Encontramos que varias acciones y discursos del gobierno mexicano produjeron la criminalización -a través, sobre todo, de su coyotización- tanto práctica como discursiva de PSF. La coyotización que sufrieron los miembros de esta OSC tiene un trasfondo político que, yendo más allá de los efectos punitivos y difamatorios que pueden tener sobre estos defensores de los migrantes y en disuadir las actividades que estos realizan, tiene que ver con su relación con Estados Unidos.

\section{Del delito de tráfico de personas a la criminalización de los defensores}

Se denomina coyotes, polleros o traficantes/contrabandistas de personas a quienes ayudan a uno o más migrantes a cruzar fronteras y territorios de manera irregular a cambio de una determinada cantidad de dinero (Torre Cantalapiedra, 2018). La actividad que estos coyotes realizan es denominada

3 PSF es una OSC conformada por abogados y activistas centroamericanos, mexicanos y estadounidenses que ha desarrollado diversos programas respecto a los migrantes en tránsito por México, entre ellos, el de acompañamiento de personas en su ruta hacia Estados Unidos (Linthicum, 2018; Ureste, Pradilla, 2019). 
tráfico/contrabando de personas o coyotaje y está fuertemente sancionada por los estados que lo consideran un delito grave o muy grave ${ }^{4}$. En México, el artículo 159 de la Ley de Migración (LM, 2011) señala la imposición de penas prisión (ocho a dieciséis años) y fuertes multas a quienes lleven a cabo actividades de tráfico de personas ${ }^{5}$.

Cabe mencionar que el tráfico, a diferencia de la trata ${ }^{6}$, no es un delito contra las personas y que si bien es cierto que algunos coyotes llevan a cabo prácticas que suponen un riesgo para la integridad física de quienes contratan sus servicios -por ejemplo, robar o abandonar a los migrantes ${ }^{7}$ - lo cierto es que los migrantes tratan de minimizar los riesgos acudiendo a sus coyotes y guías de confianza -aquellos que cumplen con lo acordado.

Los discursos dominantes sobre el coyotaje y los coyotes en Norteamérica y Centroamérica son los producidos por los actores estatales -y reproducidos por los medios de comunicación de masas- que sostienen un discurso muy negativo respecto a dicha actividad y sus protagonistas (Spener, 2008; Torre Cantalapiedra, 2018). En un análisis de las noticias de la prensa mexicana durante la crisis humanitaria de los niños, niñas y adolescente migrantes en el año 2014, Torre Cantalapiedra (2018) encuentra que la imagen que se ofrece del coyotaje es la de una actividad lucrativa basada en el engaño de migrantes ingenuos, causante de situaciones de crisis migratoria y considerada un negocio ilícito asociado a otros delitos y en manos del crimen organizado. Mientras que sus protagonistas, los coyotes, serían personas sin escrúpulos y poco confiables que se lucran estafando a los migrantes -caracterizados como víctimas- a los que con frecuencia abandonarían en el camino.

Sin pretender afirmar que los coyotes actúan de forma solidaria y desinteresada, lo cierto es que las imágenes que los discursos gubernamentales sostienen respecto a esta actividad y quienes la protagonizan están sesgadas, incompletas y simplificadas. Frente a estas visiones algunos trabajos

4 En los noventa se empezó a buscar una respuesta concertada internacionalmente a estas actividades de tráfico de personas o coyotaje -puesto que las consideraban mayormente como actividades realizadas por el crimen organizado y que victimizaban a los migrantes. En el año 2004 entró en vigor el "Protocolo contra el tráfico ilícito de migrantes" que exige la penalización de este tipo de conductas (UNODC, 2011).

5 Además, el artículo 160 de la LM (2011) señalan una serie de agravantes por los cuales las penas serán superiores.

6 El coyotaje o tráfico de personas es algo muy diferente de la trata de personas. Sin ánimo agotar el debate respecto a ambas figuras, se puede señalar que la primera actividad "es voluntario y se configura como un delito contra el Estado), mientras que el objetivo de la trata es la explotación de la persona, independientemente de si cruza fronteras internacionales o no (es forzada o fraudulenta, considerada un delito contra la persona)" (Sorolla Fernández, Moreira Seijos, 2014).

Los datos de devueltos por las autoridades estadounidenses y mexicanas de la Encuesta sobre Migración en la Frontera Sur (Emif Sur, 2018), muestran que este fenómeno del abandono de migrantes es muy infrecuente. 
académicos afirman que acudir a los servicios de coyotaje es una estrategia de supervivencia extendida entre los migrantes en Centroamérica y México para lograr sus objetivos migratorios (Spener, 2008) ${ }^{8}$.

La persecución penal del coyotaje perjudica a los migrantes, ya sea de manera indirecta, pues ven como estos servicios se encarecen a medida que los castigos que las autoridades imponen a los coyotes se endurecen y tienen más dificultades para acudir a los mismos como estrategia de tránsito. Asimismo, la persecución del delito de tráfico de personas está acompañada de detección, detención y deportación de migrantes. Esto quiere decir que cuantos más medios se destinan a perseguir el delito de tráfico, más medios se dedican a la persecución de los migrantes en tránsito irregular.

Por otra parte, el delito de tráfico de personas ha sido empleado en México para amedrentar y criminalizar las prácticas solidarias con migrantes y defensores de los migrantes. Este fue el caso de María Concepción Moreno Arteaga, quien fue detenida en 2015 por alimentar a un grupo de migrantes hondureños y sentenciada a 6 años de cárcel por cargos de tráfico de personas, de los que cumplió dos años y media antes de ser absuelta y liberada gracias a la defensa legal proporcionada por el Centro Prodh (Centro Prodh, 2007; Parrini Roses, Alquisira Terrones, 2019). O el caso de Heyman Vázquez Medina en 2007, este sacerdote fue informado por un agente federal de una denuncia anónima que lo señalaba como pollero; el caso fue finalmente cerrado por falta de pruebas (Centro Prodh, 2007).

En 2008 se produce un cierto avance para prevenir acciones jurídicamente incorrectas con base en el delito de tráfico de personas, pues se exigía obtener un beneficio económico para que se aplicase el delito de tráfico de personas (Aranda, 2008). En esta misma línea, el párrafo final del artículo 159 de la LM (2011) dispone que "no se impondrá pena a las personas de reconocida solvencia moral, que por razones estrictamente humanitarias y $\sin$ buscar beneficio alguno, presten ayuda a la persona que se ha internado en el país de manera irregular, aun cuando reciban donativos o recursos para la continuación de su labor humanitaria" (Congreso de la Unión, 2017, art. 159, último párrafo).

Estos cambios legales parecen no ser suficientes para detener los procesos de criminalización de los defensores de los migrantes a través de su incriminación como coyotes. Por ejemplo, en 2017, el Instituto Nacional de Migración (INM) denunció ante la Procuraduría General de la República (PGR) a uno de los sacerdotes de La 72 - Hogar Refugio, Fray Bernardo Molina Esquiliano, por tráfico de personas (La 72 y Red TDT, 2017).

${ }_{8}$ Los datos de la Emif Sur refieren a que se trata de una estrategia para el tránsito por México muy extendida (véase, París Pombo, 2017; El Colef et alii, 2019). 
[...] [N]uestro equipo recoge a las personas que vienen en la carretera y les ofrece llevarlas a Tenosique, a La 72 para acogerlas y empezar un acompañamiento integral. Esto ha sido visto por las autoridades y especialmente el INM, como tráfico de personas. [...] las autoridades de los tres niveles de gobierno no solo no han hecho lo que les corresponde sino que criminalizan nuestra labor y peor, utilizan el sistema penal para frenarnos, intimidarnos, acosarnos. (La 72 y Red TDT, 2017)

La criminalización de los defensores de los migrantes a través del delito de tráfico no es una tendencia que se dé exclusivamente en México, se han documentado casos en varios países: Estados Unidos, Marruecos, Honduras y Grecia (García, 2018; Martín, 2019; AI, 2019; FLD et alii, 2019). De hecho, la persecución que denuncian los defensores de los migrantes en México, no puede entenderse sin la influencia de las autoridades estadounidenses, quienes de acuerdo con Al (2019) han emprendido una campaña de hostigamiento jurídico de motivación política en contra de los defensores de los migrantes con base en los delitos de tráfico de personas -ya sea que en última instancia estos procesos no tengan visos de prosperar ante las cortes de justicia de aquel país por su improcedencia.

En abril de 2017, el fiscal general de Estados Unidos ordenó a los fiscales federales del Departamento de Justicia (DOJ, por sus siglas en inglés) la persecución "enérgica" los delitos de tráfico de personas. Entre ellos está la sección 1324 del título 8 del Código Federal de Estados Unidos la legislación estadounidense relativa a toda persona que "inste" o "induzca" a un extranjero a ir o entrar a territorio estadounidense ilegalmente; sin embargo, mientras apenas se incrementó el procesamiento por tráfico de personas, con arreglo a esta disposición se incrementó la frecuencia de procesamientos contra los defensores por cargos de tráfico, con el objetivo de disuadirlos de realizar sus actividades humanitarias (Al, 2019).

La persecución de los defensores de los migrantes como si se tratase de traficantes de personas por parte del DOJ y del Departamento de Seguridad Nacional (DHS, por sus siglas en inglés) se habría realizado en flagrante violación de la legislación estadounidense y con la colaboración del gobierno mexicano (Al, 2019).

\section{Metodología}

Para dar cuenta de los procesos de criminalización que enfrentan los defensores de los migrantes por parte de los actores estatales se optó por un estudio de caso de particular relevancia: el de PSF y que afectó destacadamente a uno de sus integrantes Irineo Mujica9 ${ }^{9}$. Los estudios de caso son especialmente

9 Mujica, quien posee la doble nacionalidad mexicana y estadounidense, ha sido defensor de los derechos de personas migrantes desde hace más de 20 años y es coordinador de PSF (FLD et alii, 2019) y ha sido fundador de varios albergues en México. 
ventajosos para dar repuesta a cómo y por qué ocurren fenómenos sociales complejos en los que participan múltiples actores y que previamente han sido poco investigados.

La elección de este caso se debe primero a su carácter mediático ${ }^{10}$ que permite tener una mayor diversidad de fuentes de datos para el análisis: hemerográficas ${ }^{11}$, informes elaborados por OSC, vídeos disponibles en Internet, comunicados de prensa gubernamentales, entre otros.

Segundo, nos permite observar cómo se producen procesos de criminalización de los defensores de los migrantes en países de tránsito (en este caso, México), los cuales reciben fuertes presiones y pueden verse influenciados por países de destino (en este caso, Estados Unidos) en cuanto a sus políticas públicas respecto a las diferentes aristas del fenómeno migratorio.

Tercero, este caso permite observar las derivaciones que el discurso y acciones que criminalizan a los defensores tienen sobre las nuevas formas de tránsito migratorio, como son las caravanas de migrantes, especialmente, en términos de criminalización de estas marchas y de sus participantes.

\section{El caso de PSF e Irineo Mujica}

\section{El contexto migratorio del caso: De los "vía crucis" a las caravanas de finales de 2018}

Los vía crucis migrantes fueron manifestaciones político-religiosas diversas y en constante cambio integradas por migrantes y activistas promigrantes -laicos y religiosos- que bajo diferentes lemas recorrieron varias rutas migratorias por México, realizando distintas protestas y denuncias (Vargas Carrasco, 2017; París Pombo, 2018). La situación de tránsito irregular de muchos de los participantes supuso varios "enfrentamientos" entre estas marchas y las autoridades mexicanas cuyas respuestas a las mismas fueron contrastantes: desde la represión hasta el apoyo.

Entre 2017 y 2018, PSF organizó tres caravanas Vía Crucis que permitieron que cientos de migrantes viajaran desde la frontera con Guatemala hasta Estados Unidos, entre ellos el Vía Crucis "Migrantes en la Lucha" en marzo de 2018 (Linthicum, 2018). Si estas marchas habían tenido frecuentemente atención de los medios nacionales, especialmente cuando se producían confrontación con las autoridades mexicanas, la de 2018 adquirió relevancia

${ }^{10}$ Debido a la participación de PSF en las caravanas, a las declaraciones de altos funcionarios del gobierno mexicano sobre tal OSC en relación con el fenómeno de las caravanas, al hostigamiento realizado a PSF por parte de las autoridades de Estados Unidos y a la posterior detención de Mujica.

11 Noticias, entrevistas y reportajes en diversos medios de comunicación que permiten recuperar las voces de los actores gubernamentales de alto nivel y de defensores de los migrantes, asimismo, las acciones realizadas por los mismos. 
internacional a medida que el presidente Trump tuiteó repetidamente en contra de la misma (Semple, 2018). El vicepresidente Mike Pence dijo que los migrantes de las caravanas eran víctimas, que estaban siendo explotados por activistas políticos en favor de una frontera abierta y por los medios (Alvarado, 2018). Asimismo, algunos miembros del partido republicano criticaron abiertamente a PSF (Mcaul citado por Schatz, 2018).

La labor de PSF en este Vía Crucis de 2018 fue la de acompañar a migrantes y refugiados en su viaje, proveerles de ayuda humanitaria y asistencia legal, a la par, que junto con ellos reivindicar sus derechos (Martínez Hernández-Mejía, 2018). Asimismo, se encargaron de la negociación con el gobierno de México para obtener los "permisos de salida", entre ellos Irineo Mujica (Durand Arp-Nisen, 2019).

A mediados del mes de octubre de 2018, un grupo de migrantes hondureños, que los medios de comunicación y autoridades de varios países llamaron "caravana migrante", partió de Honduras con el objetivo de viajar juntos hasta Estados Unidos; la difusión de la existencia de esta caravana por diversos medios hizo que la misma creciese rápidamente con personas procedentes mayormente de Honduras, El Salvador y Guatemala (Torre Cantalapiedra, Mariscal Nava, 2019). Una vez en territorio mexicano, PSF apoyó a esta caravana de manera similar a la que lo hicieron en caravanas anteriores. Según El Colef (2019, p. 35) toda la experiencia acumulada por PSF en la movilización de estos Viacrucis, se constató en tal caravana de migrantes como liderazgo en el tránsito:

Así pues, con el ingreso de las personas migrantes a la ciudad de Tapachula, fue notoria la existencia de una logística propia de un movimiento más estructurado. En el avance de las personas se escuchaban las consignas de otras caravanas convocadas por Pueblos sin Fronteras, mientras que dicho avance era coordinado por un grupo de personas que portaban chalecos fluorescentes verdes, así como pancartas o lonas con consignas y banderas centroamericanas. Finalmente, una expresión de este liderazgo que asume un rol preponderante en la Caravana se hace manifiesto en las diferentes convocatorias masivas, denominadas "asambleas", en donde justamente personas relacionadas a Pueblos sin Fronteras, bajo el argumento de acompañar el proceso, asumen un rol sumamente directivo que impacta de manera expresa en los procesos de la Caravana, lo mismo en las ruedas de prensa y comunicados en medios.

Durante una marcha en solidaridad con la caravana de migrantes en Tapachula (Chiapas), Mujica fue detenido por Policías Federales y agentes del INM (Henríquez, 2018) y días después liberado. El sacerdote Heyman Vázquez señaló entonces que Mujica "está muy molesto y tiene razón porque fue detenido injustamente y por motivos políticos, ya que el gobierno no quiere que participe en la caravana de migrantes hondureños" (Vázquez citado en Henríquez, 2018). Esta detención en relación con las caravanas de migrantes de finales de 2018 no sería la última, la segunda sería mucho 
más grave al tener que afrontar cargos de tráfico de personas con una pena aparejada de hasta 24 años de prisión (FGR, 2019).

\section{Estados Unidos criminaliza a defensores de los migrantes: PSF en el punto de mira}

El gobierno de Trump ha criminalizado de forma discursiva y práctica a los defensores de los migrantes mediante diversas acciones y discursos, entre otras acciones, se destaca la campaña de hostigamiento legal en contra de los defensores que apoyaron de manera solidaria a las caravanas de migrantes empleando el delito de tráfico de personas (cuadro 1). De toda la información que se ha hecho pública se deriva que: primero, que PSF y sus miembros era uno de los objetivos de esta campaña de criminalización de Estados Unidos; segundo, que en la misma México habría cooperado en el marco de los acuerdos bilaterales de la lucha contra el tráfico de personas.

Cuadro 1 - Cronograma de los eventos relacionados con el hostigamiento de defensores de los migrantes llevado a cabo por las autoridades estadounidenses

\begin{tabular}{|c|c|}
\hline Dic. 2018 & $\begin{array}{l}\text { Desde diciembre de 2018, miembros de PSF (Elena Alderman, Jeff } \\
\text { Valenzuela, Tristan Call, Alex Mensing, Irineo Mijica, David Abud y } \\
\text { Roberto Corona), así como periodistas, abogados y activistas de otras } \\
\text { organizaciones, han sido hostigados cuando ingresaban a Estados } \\
\text { Unidos, por parte del DHS mediante retenciones prolongadas, } \\
\text { interrogatorios y registros de sus dispositivos electrónicos, entre } \\
\text { otros. En estos interrogatorios varios integrantes de PSF son señalados } \\
\text { como traficantes de personas. A varios de los interrogados por los } \\
\text { oficiales les mostraron fotos de integrantes de PSF. }\end{array}$ \\
\hline \multirow[t]{3}{*}{ Mar. 2019} & $\begin{array}{l}\text { Medios de comunicación revelaron la filtración de una base de } \\
\text { dados secreta creada por autoridades estadounidenses y mexicanas } \\
\text { titulada "Sección de Operaciones Extranjeras del Sector de San Diego: } \\
\text { Caravana Migrante } 2019 \text { Supuestos Organizadores, Coordinadores, } \\
\text { Instigadores y Periodistas". }\end{array}$ \\
\hline & $\begin{array}{l}\text { Estos archivos dejan ver que el DHS había actuado, al menos, en contra } \\
\text { de } 59 \text { activistas, periodistas y abogados por su supuesto contacto con } \\
\text { los participantes de la caravana de migrantes. El DHS afirmó entonces } \\
\text { que estaba siguiendo a personas que presenciaron o participaron en } \\
\text { el enfrentamiento violento ocurrido el } 25 \text { de noviembre de } 2018 \text { en la } \\
\text { frontera México-Estados Unidos. }\end{array}$ \\
\hline & $\begin{array}{l}\text { La hoja de presentación del documento filtrado a los medios de } \\
\text { comunicación indicaba que esta operación de vigilancia de los } \\
\text { defensores de los migrantes se estaba llevando a cabo en el marco de } \\
\text { la "Iniciativa de Seguridad contra Traficantes", una operación bilateral } \\
\text { entre México y Estados Unidos. }\end{array}$ \\
\hline
\end{tabular}


May. 2019

La Oficina de Aduanas y Protección Fronteriza de los Estados (CBP, por sus siglas en inglés) publicó una carta en la que se indicaba la base jurídica de la operación de vigilancia en la sección 1324 del título 8 del Código Federal de Estados Unidos. En esta misma carta se confirmaba que la operación de vigilancia contra defensores de los migrantes se había realizado de manera conjunta entre las autoridades estadounidenses y mexicanas.

Fuente Elaboración propia con base en Al (2019) y FLD et alii (2019).

\section{La criminalización discursiva de PSF por parte de las autoridades mexicanas}

En enero de 2019, en una entrevista en radio que giraban en torno al fenómeno de las caravanas el Comisionado del INM, Tonatiuh Guillén, señaló que:

El punto central que compartimos es que son personas con muy escasa información, lo cierto es que quienes promueven este tipo de movilidades engañan a las personas, les dicen que el arribo a Estados Unidos no es difícil, que el ingreso a Estados Unidos tampoco es complicado, que lo pueden lograr de manera sencilla. ¿Estas personas son los líderes de Pueblos Sin Fronteras? [pregunta del entrevistador] Parte de ellos, son ellos, [inaudible] hay otros grupos. Este... y yo me temo, Ciro, que también hay tráfico de personas en estas promociones. (Guillén, 2019)

En este fragmento se puede observar que Guillén señala que quienes promueven estas caravanas engañan a las personas -algo que las autoridades de varios países repetidamente señalaban que hacían los coyotes con los migrantes en la crisis humanitaria de los NNAM de 2014 (Torre Cantalapiedra, 2018)-. Ante la pregunta del entrevistador, el Comisionado afirmó que PSF son parte de quienes las promueven. La respuesta continúa con una yuxtaposición ilegítima ${ }^{12}$ que, incluso sin afirmarlo de manera explícita, deja latente la idea de que PSF puede estar participando en el tráfico de personas.

En un discurso en febrero de 2019 en el Migration Policy Institute, la Secretaria de Gobernación señaló que:

[...] las caravanas. Es un nuevo fenómeno que no habíamos tenido antes. Que, por cierto, hay que ver quiénes están promoviendo... las caravanas, qué organizaciones están promoviendo estas caravanas. ¿Sí? Quienes son los líderes, cómo reclutan a la gente desde Honduras [...] estos líderes y cómo realizan este movimiento migratorio inusual pero que muy pronto se va a convertir en algo normal de caravanas hacia el Norte". Asimismo, en el turno de preguntas y comentarios añadió "Tenemos identificados a los líderes de organizaciones no gubernamentales y que están reclutando estas caravanas, concretamente hay algunos de Pueblos Sin Frontera"; prosiguió señalando que tenían identificados a personas con antecedentes penales, con ficha roja de Interpol, "incluso también

12 Aquella que establece, siquiera de un modo subliminal, una relación de causalidad entre dos hechos que se sitúan juntos, sobre todo si implica una acusación personal sin fundamento (Grijelmo, 2014). 
algunos de los líderes que estaban manejando ilegalmente. A ver, es un negocio enorme, el tráfico de personas es un negocio enorme". (Sánchez Cordero, 2019)

Como lo señala Al (2019, p. 38) "la Secretaria de Gobernación de México, hizo la peligrosa insinuación -sin ofrecer ninguna prueba ni afirmarlo abiertamente- de que Pueblo Sin Fronteras podría estar implicada en tráfico de personas en el contexto de su labor de apoyo a las caravanas de migrantes". Además, se está señalando que las OSC como PSF son las que están promoviendo la movilidad de las caravanas y que lo hacen de un modo que requiere ser investigado.

Éstas declaraciones, por parte de dos altos cargos del gobierno mexicano, promueven la coyotización/criminalización discursiva de PSF, no sólo por asociarla al tráfico de personas, sino por colocar a esta OSC en el rol que los traficantes de personas han tenido en el discurso de las autoridades de varios países los últimos años, esto es de responsables de los flujos migratorios que se han producido.

La coyotización discursiva de los defensores de los migrantes también busca la criminalización de las caravanas de migrantes. Como se observó en repetidas ocasiones el discurso de las autoridades (de Estados Unidos, México y Honduras) trató de vincular a las caravanas de migrantes y a sus participantes con actos ilícitos y que son reprobados socialmente -tráfico de personas, crimen organizado, entre otros-. Resulta hasta cierto punto ilógico pensar que las caravanas estaban organizadas por coyotes/traficantes de personas, cuando viajar en estas es una estrategia que utilizaron mayormente personas de bajos recursos que no pueden sufragar el coste de los servicios de coyotaje o para ahorrarse su elevado costo (Torre Cantalapiedra, Mariscal Nava, 2019; Varela Huerta, McLean, 2019). Inclusive algunos migrantes compatibilizaron la estrategia de ir con la caravana una parte del trayecto con acudir a los servicios de coyotaje para recorrer otra parte del territorio (Torre Cantalapiedra, Mariscal Nava, 2019). En cualquier caso, que hubiese personas con récord criminal o coyotes dentro o alrededor de las caravanas no deslegitima esta marcha en absoluto, pues la inmensa mayoría de los integrantes de tales caravanas eran personas en busca de una vida mejor, muchas de ellas necesitadas de protección internacional.

\section{La coyotización práctica: la detención de Irineo Mujica en México y su poder simbólico}

El 5 de junio 2019 fueron detenidos Irineo Mujica -que como se vio fue uno de los integrantes de PSF más activos en el apoyo de los Viacrucis y después de las primeras caravanas de migrantes- y Cristóbal Sánchez, activista promigrante, por agentes de la Fiscalía General de la República (FGR) por orden de un juez del estado Chiapas: 
Los mandamientos se cumplimentaron contra Irineo " $\mathrm{M}$ ", por la probable comisión del delito de transporte de migrantes con la agravante que dicha conducta se haya realizado respecto de niñas, niños y adolescentes; y contra Cristóbal "S", por la probable comisión del delito de introducción de personas a territorio nacional sin la documentación correspondiente. (FGR, 2019)

De este modo Mujica enfrentaba cargos de tráfico que podrían conducirle a 24 años de prisión. Los hechos de lo que se le acusaba eran los de "de trasladar a tres personas de origen hondureño a la frontera norte de Monterrey, Nuevo León, a cambio de un pago de 7 mil pesos" (Redacción AN/GV, 2019). Pero Pueblo Sin Fronteras y el propio Mujica denunciaban que estos "delitos fueron fabricados"" (Mujica citado en Redacción AN/GV, 2019). Varios académicos y miembros de OSC denunciaron que se trataba de una persecución política de estos dos activistas. Así, por ejemplo, Varela Huerta y McLean (2019, p. 178) calificaron estos hechos como "una más de las detenciones arbitrarias con fines persuasivos que el Gobierno mexicano ejerce desde hace más de una década contra quienes tejen solidaridad con los migrantes".

El juez determinó no procesarlos, pues consideró que ninguno de los dos se encontraba en el lugar señalado por los denunciantes, pero también indicó que el Ministerio Público podía seguir con sus pesquisas (Pradilla, 2019). Tras su liberación Mujica consideró que su detención tenía una motivación política, en sus propias palabras: "yo y los migrantes somos la moneda de pago para quedar bien con Donald Trump. Fui el cordero sacrificado porque esto no fue más que un montaje" (Mujica citado en Pradilla, 2019).

Las detenciones de Mujica y de Sánchez sucedieron en el marco de las negociaciones, y posterior acuerdo alcanzado el 7 de junio, tras la amenaza del gobierno de Estados Unidos de imponer aranceles a los productos mexicanos si México no conseguía reducir la migración que llegaba hasta la frontera con Estados Unidos para cruzar de manera irregular o solicitar asilo. En el acuerdo, además de señalarse que México realizaría medidas para frenar la migración en tránsito irregular, se afirmaba que "México está tomando acciones decisivas para desmantelar las organizaciones de tráfico y trata de personas, así como sus redes de financiamientos y transporte ilegales" (US Department of State, 2019) que según Al (2019) hacía referencia a las detenciones de Mujica y de Sánchez dos días antes.

El presidente López Obrador (2019) señaló que estas dos detenciones no correspondían a actuar por consigna de Estados Unidos, pero eso no anula la fuerza político-simbólica de la detención de Mujica, que el gobierno de México conocía desde el momento en que estuvieron cooperando con el gobierno estadounidense en su campaña contra defensores que participaron en las caravanas de migrantes, la cual tenía como uno de sus objetivos principales PSF. Con esta acción México estaría mandando un mensaje alto y claro a Donald 
Trump: el gobierno mexicano es un aliado de su lucha contra la migración, no solo deteniendo a los propios migrantes sino combatiendo con aquellos que apoyan/facilitan su movilidad, ya sean coyotes o defensores de los migrantes; precisamente en el contexto del "acuerdo de los aranceles".

\section{Comentarios finales}

Las acciones y discursos del gobierno mexicano generaron una criminalización tanto práctica como discursiva de PSF y sus miembros a través del delito de tráfico de personas. A diferencia de otras coyotizaciones de los defensores de los migrantes que se han producido en el pasado, que principalmente buscaban disuadir a quienes defienden a los migrantes de realizar sus legítimas actividades humanitarias, las acciones realizadas por el gobierno de México respecto a PSF en 2019 parecen tener una mayor trascendencia en términos políticos.

La coyotización discursiva a raíz de las intervenciones públicas de dos altos cargos del gobierno mexicano hizo ver los miembros de esta OSC como si de posibles traficantes de personas se tratase. Asimismo, en la narrativa construida por el gobierno respecto a PSF pasó a ocupar el lugar que tradicionalmente han ocupado los coyotes en el discurso respecto a la migración, esto es, responsables maliciosos de los flujos migratorios -en este caso, en forma de caravanas- que causan diferentes tipos de crisis: humanitarias, de gestión migratoria y políticas.

Además, la coyotización discursiva, no es meramente un discurso que criminaliza a estos defensores de los migrantes, sino las propias caravanas de migrantes y sus integrantes se ven salpicados, por asociación con estos supuestos coyotes. En este sentido, se deben seguir analizando los discursos que los gobiernos construyen entorno a las caravanas y que frecuentemente sitúan a sus participantes en dos extremos: el de peligrosos criminales o el de víctimas ingenuas.

La coyotización práctica analizada ha consistido en la detención de Irineo Mujica, miembro de PSF por cargos de tráfico de personas que no han podido ser demostrados ante los tribunales. Muchos académicos e integrantes de OSC han considerado esta detención como arbitraria, injusta, realizada por motivos políticos, entre otros. Si estuvieran en lo cierto, se estaría tratando de disuadir e impedir por medio de execrables actos ilegales que los defensores de los migrantes realicen sus actividades humanitarias, todo ello, en detrimento de las personas migrantes que ya no recibirían su apoyo.

En cualquier caso, tanto si se trata de una detención hecha respetando todas las garantías de ley o de un infame delito construido, esta incriminación tuvo sin duda una gran fuerza política-simbólica para enviar un mensaje al 
gobierno de Estados Unidos de que México está dispuesto a cooperar en los diversos frentes de la política antiinmigrante del gobierno estadounidense.

El caso de PSF permite observar que la criminalización de los defensores de los DD.HH. de los migrantes que se produce en "países de tránsito" (como México) es en buena medida resultado de las presiones, chantajes o incentivos por parte de países receptores (como Estados Unidos) que pretenden imponer sus políticas de contención migratoria que, entre otras estrategias, incluyen la persecución del delito de tráfico de personas y el hostigamiento a los defensores de migrantes. Por lo tanto, otros casos de criminalización de defensores en países de tránsito, como las acusaciones de tráfico de migrantes a Helena Maleno en Marruecos, deben ser examinados de igual forma desde la óptica de la externalización de fronteras.

Finalmente, se quiere señalar que hemos referido a ambos tipos de coyotización por separado, pero en la realidad social se yuxtaponen de forma simultánea. Por un lado, la coyotización discursiva favorece que se produzca la práctica; por otro lado, las acciones de la coyotización práctica pueden implicar enviar un mensaje y tienen por lo tanto una interpretación discursiva.

\section{Bibliografía}

ALVARADO, Gonzalo. Pence dice que activistas y la prensa "explotan" a los inmigrantes centroamericanos de la caravana. CNN, 2018. Disponible en: $<$ https://cnnespanol.cnn.com/video/caravana-inmigrantes-mike-pencerecorrido-frontera-calexico-mexicali-live-dusa-gonzalo-alvarado/>. Acceso en: 22.12.2019.

AMNISTÍA INTERNACIONAL (AI). 'Salvar vidas no es delito'. Hostigamiento jurídico de motivación política, ejercido por EE.UU. contra los defensores de derechos humanos de las personas migrantes. 2019. Disponible en: <https://www. amnesty.org/es/documents/amr51/0583/2019/es/> . Acceso en: 22.12.2019.

ARANDA, Jesús. Permite la Corte asistir a migrantes por razones humanitarias y sin fines de lucro. La Jornada, 2008. Disponible en: <http://www.jornada.unam. $\mathrm{mx} / 2008 / 03 / 06 /$ index . php? section $=$ politica\&article $=021 \mathrm{n} 1$ pol $>$. Acceso en: 22.12.2019.

CENTRO DE DERECHOS HUMANOS "MIGUEL AGUSTÍN PRO JUÁREZ" - Centro Prodh. El asalto a la defensa de los derechos humanos de los migrantes. 2007. Disponible en: <https://centroprodh.org.mx/wp-content/uploads/2017/12/ El-asalto-a-la-defensa-de-los-derechos-de-los-migrantes.pdf $>$. Acceso en: 22.12.2019.

CONGRESO DE LA UNIÓN DE LOS ESTADOS UNIDOS MEXICANOS. Ley de Migración, 2011, y reformas posteriores. 2017. Disponible en: <http://www. diputados.gob.mx/LeyesBiblio/ref/Imigra.htm>. Acceso en: 22.12.2019. 
DURAND ARP-NISEN, Jorge. Política Migratoria: entre el discurso, la práctica y la coyuntura. Foro Internacional, p. 1021-1047, 2019.

EL COLEGIO DE LA FRONTERA NORTE (El Colef). La caravana de migrantes centroamericanos en Tijuana 2018-2019 (Segunda etapa). 2019. Disponible en: $<$ https://www.colef.mx/estudiosdeelcolef/la-caravana-de-migrantes-centroamericanosen-tijuana-2018-2019-segunda-etapa/> . Acceso en: 22.12.2019.

EL COLEGIO DE LA FRONTERA NORTE; SEGOB/UPMRIP; SEGOB/CONAPO; SRE; STPS; CONAPRED; SEDESOL. Encuesta sobre Migración en la Frontera Sur de México. Informe anual de Resultados 2018. 2019. Disponible en: < https:// www.colef.mx/emif/informes.php>. Acceso en: 22.12.2019.

FARET, Laurent. Mobilités internationales et ressources en contexte métropolitain: trajectoires centraméricaines à Mexico. EchoGéo, n. 39, p. 1-16, 2017.

FISCALÍA GENERAL DE LA REPÚBLICA (FGR). Comunicado FGR 277/19. FGR informa sobre casos migratorios. 6 de junio de 2019. Disponible en: <https:// www.gob.mx/fgr/prensa/comunicado-fgr-277-19-fgr-informa-sobre-casosmigratorios $>$. Acceso en: 22.12.2019.

FLD - FRONT LINE DEFENDERS, RED TDT, LIS-JUSTICIA EN MOVIMIENTO, PROGRAMA DE ASUNTOS MIGRATORIOS, UNIVERSIDAD IBEROAMÉRICA CIUDAD DE MÉXICO. Defensores sin muros: personas defensoras de derechos humanos, criminalizadas en Centroamérica. 2019. Disponible en: < https://www. frontlinedefenders.org/es/statement-report/defenders-beyond-borders-migrantrights-defenders-under-attack-central-america>. Acceso en: 22.12.2019.

GARCÍA, Ter. El caso de Lola Gutiérrez: hasta 10 años de cárcel por intentar ayudar a un menor kurdo a reunirse con su familia. El Salto, 2018. Disponible en: <https:// www.elsaltodiario.com/refugiados/lola-gutierrez-cgt-10-anos-carcel-ayudarmenor-kurdo-reunirse-familia-refugiados-grecia > . Acceso en: 22.12.2019.

GRIJELMO, Álex. El estilo del periodista. España: Taurus Pensamiento, 2014.

GUILLÉN, Tonatiuh. Viene otra caravana migrante de Honduras; se respetarán sus derechos: INM. Radioformula. 2019. Disponible en: < https://www.radioformula. com.mx/noticias/20190115/viene-otra-caravana-migrante-de-honduras-serespetaran-sus-derechos-inm $>$. Acceso en: 22.12.2019.

HENRÍQUEZ, Elio. Liberan al activista Irineo Mújica. La Jornada, 2018. Disponible en: <https://www.jornada.com.mx/2018/10/21/politica/006n2pol>. Acceso en: 22.12.2019.

LA 72-HOGAR-REFUGIO PARA PERSONAS MIGRANTES y RED TDT. Nueva embestida del INM en contra del personal de la 72. 2017. Disponible en: < http:// redtdt.org. $\mathrm{mx} / \mathrm{p} \mathrm{p}=8872>$. Acceso en: 22.12.2019.

LINTHICUM, Kate. Pueblos Sin Fronteras usa las caravanas para dar a conocer la situación de los migrantes, pero... ìha sido contraproducente? Los Ángeles Times, 2018. Disponible en: <https://www.latimes.com/espanol/eeuu/la-espueblo-sin-fronteras-usa-las-caravanas-para-dar-a-conocer-la-situacion-de-losmigrantes-pero-ha-sido-20181206-story.html/>. Acceso en: 22.12.2019. 
LÓPEZ OBRADOR, Andrés Manuel. Versión estenográfica de la conferencia de prensa matutina del presidente Andrés Manuel López Obrador. 2019. Disponible en: <https://lopezobrador.org.mx/2019/06/06/version-estenograficade-la-conferencia-de-prensa-matutina-del-presidente-andres-manuel-lopezobrador-98>. Acceso en: 22.12.2019.

MARTíN, M. La activista Helena Maleno anuncio el archivo de su causa por supuesto tráfico de personas. El país, 2019. Disponible en: <https://elpais. com/politica/2019/03/11/actualidad/1552291998_586702.html>. Acceso en: 22.12.2019.

MARTINEZ HERNÁNDEZ-MEJÍA, Iliana. Reflexiones sobre la caravana migrante. Análisis Plural, 2018. Disponible en: <https://rei.iteso.mx/bitstream/ handle/11117/5616/S3\%20Reflexiones\%20sobre\%20la\%20caravana\%20 migranteAjustado.pdf?sequence $=2>$. Acceso en: 22.12.2019.

PARÍS POMBO, María Dolores. Violencias y migraciones centroamericanas en México. México: El Colegio de la Frontera Norte, 2017.

PARÍS POMBO, María Dolores. Las caravanas de migrantes, su representación política y los derechos humanos de los migrantes. Observatorio de legislación y política migratoria de El Colef. 2018. Disponible en <http://observatoriocolef. org/?boletin=boletin-de-prensa-las-caravanas-de-migrantessu-representaciony-los-derechos-humanos-de-los-migrantes > . Acceso en: 22.12.2019.

PARRINI ROSES, Rodrigo; ALQUISIRAS TERRONES, Luisa. Desplazamientos discursivos y transformaciones institucionales en las prácticas de solidaridad hacia migrantes centroamericanos en México. Migraciones Internacionales, v. 10, n. 36, p. 1-19, 2019.

PRADILLA, Alberto. Los defensores de migrantes Cristóbal Sánchez e Irineo Mujica quedan libres. Animal Político, 2019. Disponible en: <https://www. animalpolitico.com/2019/06/cristobal-sanchez-irineo-mujica-defensormigrantes-detenido $>$. Acceso en: 22.12.2019.

REDACCIÓN AN /GV. Hay represión y acoso contra quienes nos oponemos a que México sea cómplice del racismo de EU: Activista. Aristegui Noticias, 2019. Disponible en: <https://aristeguinoticias.com/1807/mexico/hay-represion-yacoso-contra-quienes-nos-oponemos-a-que-mexico-sea-complice-del-racismode-eu-activista > . Acceso en: 22.12.2019.

SÁNCHEZ CORDERO, Olga. Una nueva política migratoria para una nueva era: Una conversación con la Secretaria de Gobernación Olga Sánchez Cordero. Migration Policy Institute, 2019. Disponible en: < https://www.migrationpolicy. org/events/una-conversacion-con-la-secretaria-gobernacion-Mexico>. Acceso en: 22.12.2019.

SCHATZ, Bryan. Key Arizona Republican Freaks Out Over "Another Generation of DACA-like People". Mother Jones, 2018. Disponible en: <https://www. motherjones.com/politics/2018/05/key-arizona-republican-freaks-out-overanother-generation-of-daca-like-people/> . Acceso en: 22.12.2019. 
SEMPLE, Kirk. Los tuits de Trump convierten al Viacrucis Migrante en un asunto internacional. The New York Times, 2018. Disponible en: < https://www.nytimes. com/es/2018/04/03/trump-caravana-migrante>. Acceso en: 22.12.2019.

SOROLLA FERNÁNDEZ, Ileana; MOREIRA SEIJOS, Onésimo. Intersecciones entre la migración irregular, el tráfico y la trata de migrantes. El caso de Cuba. Revista Mundi Migratios, v. II, n. 1, 2014.

SPENER, David. El Apartheid global, el coyotaje y el discurso de la migración clandestina: distinciones entre violencia personal, estructural y cultural. Migración y Desarrollo, n. 10, p. 127-156, 2008.

TORRE CANTALAPIEDRA, Eduardo. Representaciones mediáticas y migración: análisis de discursos periodísticos respecto al coyotaje en la crisis migratoria de 2014. Migración y Desarrollo, v. 16, n. 30, p. 157-178, 2018.

TORRE CANTALAPIEDRA, Eduardo; MARISCAL NAVA, Dulce María. Batallando con fronteras: estrategias migratorias en tránsito de participantes en las caravanas de migrantes. Congreso 2019 Sociedad Mexicana de Sociología, Universidad Nacional Autónoma de México, México, 2019.

UNODC. Marco de Acción Internacional para la aplicación del Protocolo contra el tráfico ilícito de migrantes. 2011. Disponible en: <https://www.acnur. org/fileadmin/Documentos/Publicaciones/2017/11435.pdf $>$. Acceso en: 22.12.2019.

URESTE, Manuel; PRADILLA, Alberto. ¿Por qué detuvieron a Irineo y Cristóbal, defensores de derechos de migrantes? Animal político, 2019. Disponible en: <https://www.animalpolitico.com/2019/06/por-que-detuvieron-defensoresmigrantes/>. Acceso en: 22.12.2019.

US DEPARMENT OF STATE. U.S.-Mexico Joint Declaration. 2019. Disponible en: < https://www.state.gov/u-s-mexico-joint-declaration/>. Acceso en: 23.12.2019.

VARELA HUERTA, Amarela; MCLEAN, Lisa. Caravanas de migrantes en México: nueva forma de autodefensa y transmigración. Revista CIDOB d'Afers Internacionals, n. 122, p. 163-185, 2019.

VARGAS CARRASCO, Felipe de Jesús. El vía crucis del migrante: demandas y membresía. TRACE Procesos Mexicanos y Centroamericanos, n. 73, p. 117-133, 2017. 